\title{
Clinical-pathological findings of otitis media and media-interna in calves and (clinical) evaluation of a standardized therapeutic protocol
}

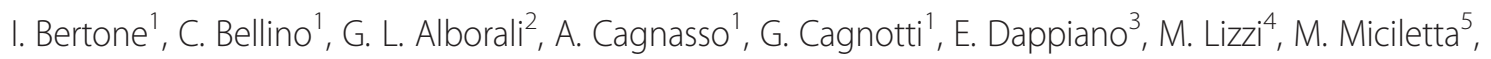
A. Ramacciotti ${ }^{6}$ P. Gianella ${ }^{1}$ and A. D'Angelo ${ }^{1^{*}}$

\begin{abstract}
Background: The aims of this field trial were to describe the clinical-pathologic findings in calves with otitis media $(\mathrm{OM})$ and media-interna (OMI), to evaluate, through the development of a scoring system, the effectiveness of a standardized therapeutic protocol, and to identify the causative pathogens and their possible correlation with concurrent respiratory disease. All animals underwent physical and neurological examinations at three experimental time points: at diagnosis/beginning of treatment (T0), 1 week (T1) and 2 weeks (T2) after therapy was started, respectively. Follow-up telephone interviews with animal owners were conducted 1 month later. The therapeutic protocol consisted of tulathromycin (Draxxin ${ }^{\oplus}$; Zoetis), oxytetracycline hydrochloride (Terramicina $100^{\oplus}$; Zoetis), and carprofen (Rimadylø; ;oetis).

Results: Twenty-two calves were enrolled. Physical and otoscopic examination at T0 revealed monolateral and bilateral otorrhea in 16 and 6 calves, respectively, with peripheral vestibular system involvement in calves presenting with neurological signs $(n=17 ; 77 \%)$. A significant improvement of clinical and neurological scores was observed in 20 (90\%) calves, a full recovery in only 1 (5\%). One calf worsened between T0 and T1 and it was removed from the study. None of the other animals showed a worsening of clinical conditions and/or required further treatments at one month follow up. Mycoplasma bovis was isolated in $89 \%$ of the affected ears either alone or together with P. multocida $(n=5)$, Streptococcus spp. $(n=1)$, Staphylococcus spp. $(n=1)$, and Pseudomonas spp. $(n=1)$. M. bovis either alone or together with these bacteria was also isolated from the upper and/or lower respiratory tract in 19 (86\%) calves.

Conclusions: This is the first prospective study to evaluate the effectiveness of a standardized therapeutic protocol for the treatment of OM/OMI in calves. The therapy led to clinical improvement in the majority of the calves. Persistence of mild clinical-neurological signs did not compromise productive performance. The numerical scoring system for clinical and neurological signs permitted objective evaluation of response to therapy. $M$. bovis was the pathogen most often isolated. This finding should be considered in the treatment of OM/OMI in calves. Moreover, respiratory tract infection should not be underrated, since it is one of the major risk factors for the development of OM/OMI.
\end{abstract}

Keywords: Bovine, Calves, Neurology, Otitis, Therapy

\footnotetext{
* Correspondence: antonio.dangelo@unito.it

'Department of Veterinary Science, University of Turin, Grugliasco, Italy

Full list of author information is available at the end of the article
} 


\section{Background}

Otitis media (OM) and media-interna (OMI) are common diseases in cattle. They can occur either sporadically or as an outbreak [1], causing economic losses [2]. Young animals, from 1 week to 18 months of age, are usually affected [2,3], although OM has also been reported in an adult cow [4]. No gender predisposition has been demonstrated but inclement weather has been associated with increased incidence [5-9]. Reportedly, beef calves are more often affected, though the incidence of OMI seems to be rising among dairy calves, as well $[6-8,10,11]$. OMI occurs frequently in association with respiratory infections, and the same causative pathogens have been isolated $[1,8]$. The most common route of infection is through the Eustachian (auditory) tube. The pathogens can also reach the middle ear by hematogenous spread or by migration from the external ear, which occurs primarily in cases of parasitic otitis $[1,6,8,12,13]$. Mycoplasma bovis, either alone or in association with other bacteria, is considered one of the main etiological agents of OMI in calves $[1,8,10,13]$. Clinical signs of OM and OMI vary from conjunctival discharge, pain, obtundation, poor appetite and pyrexia $[5,7,8,14,15]$ to neurologic manifestations secondary to facial nerve (cranial nerve VII) and vestibulocochlear nerve (cranial nerve VIII) dysfunctions [1]. Purulent aural discharge may appear into the external acoustic meatus in association with rupture of the tympanic membrane. Increased pressure into the tympanic bulla due to the exudate filling the cavity can cause the membrane to rupture $[2,9]$. Complications of OMI are ill thrift and intracranial extension with worsening of neurological signs $[8,11]$. To prevent economic losses due to treatment costs and weight faltering, diagnosis should be made during the early or subclinical stages of the disease $[12,16]$. The presumptive clinical diagnosis is based on physical and neurological evaluation and can be confirmed by otoscopic examination and other diagnostic imaging techniques $[8,11,16,17]$. A definitive diagnosis of $\mathrm{OM}$ and OMI is reached at necropsy, as well [1]. Treatment in the acute stages has been effective, while poor response to therapy has been related to chronicity or development of complications $[1,2,8,12]$.

Prospective studies on the effectiveness of therapeutic standardized protocols for $\mathrm{OM}$ and $\mathrm{OMI}$ in calves are lacking to date. The hypothesis of this study were to evaluate if a standardized therapeutic protocol can be used in the treatment of OM and OMI in veal calves and if it is possible to assess objectively the response to therapy. The primary aims of this field trial were (1) to describe the clinical-pathologic findings in calves with $\mathrm{OM}$ and OMI and (2) to evaluate, through the development of a scoring system, the effectiveness of a standardized therapeutic protocol. A secondary objective was to identify causative pathogens and their possible correlation with concurrent bovine respiratory disease (BRD) in Italy, in the referred population.

\section{Methods}

The study was performed according to ethical recommendations, animal welfare considerations and regulations (Directive 98/58/EC and Italian Decree Law 146/2001). Moreover, for any patient referred at Teaching Hospital of the Department of Veterinary Science of Turin (Italy) the owner or an agent for the owner had to read and sign an informed owner consent in order to authorize any veterinary assessment and treatment needed for his/her animal. Calves referred to the Teaching Hospital of the Department of Veterinary Science of Turin (Italy) between February 2013 and December 2014 for suspicion of acute OM and OMI were selected for the study. Animals were recruited if they had not received treatment, had undergone physical and neurological examination, if $\mathrm{OM}$ and/or $\mathrm{OMI}$ were confirmed by aural examination by means of otoscopy/endoscopy, and if follow-up records were available. All animals underwent bilateral otoscopic examination with a hand-held otoscope (Heine Beta ${ }^{\circ} \mathrm{TR} 3.5 \mathrm{~V}$ rechargeable handle, Heine G-002.21.301 slit illumination head, $65 \mathrm{~mm} \times 6 \mathrm{~mm}$ diameter closed specula, Heine Optotechnik, Herrsching, Germany); in selected cases, endoscopic examination was carried out using a laparoscope (Karl Storz GmBH, Tuttlingen, Germany, Ottica Hopkins II, $2.7 \mathrm{~mm} \times 15 \mathrm{~cm}$ ).

\section{Physical and neurological examination}

Physical and neurological examinations were performed at three experimental time points: at diagnosis/beginning of treatment (T0), 1 week (T1) and 2 weeks (T2) after therapy was started, respectively. During follow-up telephone interviews with the owners 1 month after T2, information was collected on the animals' mental status, appetite, weight gain, possible worsening and further treatments. Physical examination was based on a protocol tested and optimized in a previous pilot study (data not shown). Neurological examination was performed by a boardcertified neurologist (ADA). A two-part standardized data collection form, one for physical and one for neurological findings, was completed for each animal. The scoring system for clinical signs was derived from the Calf Respiratory Scoring Chart, University of Wisconsin $[18]^{1}$. The scoring system for neurological signs was devised on the basis of a previous pilot study by the authors. Tables 1 and 2 show the numerical scoring systems used to quantify the clinical and neurological findings, respectively, at each experimental time point. A final total score (clinical + neurological scores) was then obtained for each animal at each time point. 
Table 1 Classification of severity (score) of clinical findings in calves with otitis

\begin{tabular}{|c|c|}
\hline Score & Clinical findings \\
\hline & Rectal Temperature \\
\hline 0 & $\leq 39.2^{\circ} \mathrm{C}$ \\
\hline 1 & $39.3^{\circ} \mathrm{C}<\mathrm{T}^{\circ}<40^{\circ} \mathrm{C}$ \\
\hline \multirow[t]{2}{*}{2} & $\geq 40^{\circ} \mathrm{C}$ \\
\hline & Feces \\
\hline 0 & Normal feces \\
\hline 1 & $\begin{array}{l}\text { Feces softer than normal, but no } \\
\text { diarrhea on tail }\end{array}$ \\
\hline 2 & Diarrhea but not profuse, wet tail \\
\hline \multirow[t]{2}{*}{3} & $\begin{array}{l}\text { Profuse watery diarrhea with blood } \\
\text { and fibrin, wet tail }\end{array}$ \\
\hline & Respiratory System \\
\hline 0 & No respiratory signs \\
\hline $1^{*}$ & Induced or spontaneous cough \\
\hline $1^{*}$ & Nasal discharge \\
\hline $1^{*}$ & Eye discharge \\
\hline \multicolumn{2}{|c|}{ *one point for each sign } \\
\hline & Otoscopic Examination \\
\hline 0 & Absence of purulent material \\
\hline $1^{*}$ & Presence of purulent material \\
\hline \multicolumn{2}{|c|}{${ }^{*}$ one point for each side (left/right) } \\
\hline & Joints \\
\hline 0 & No signs of arthritis \\
\hline $1^{*}$ & Presence of arthritis \\
\hline *one & \\
\hline
\end{tabular}

\section{Sample collection and analysis}

All procedures were conducted in sterile conditions to exclude sample contamination. With the exception of blood samples, all biological specimens were collected with the animal sedated with xylazine (Rompun ${ }^{\bullet}$, Bayer Health Care, Monheim, Germany) (IV $0.05 \mathrm{mg} / \mathrm{kg}$ ). Two blood venous samples (5 mL/aliquot) were collected from the jugular vein of each animal: one aliquot was collected in an EDTA tube for hemocromocytometric analysis, the other was collected into a serum vacuum tube for biochemical profile (alanine transaminase [ALT], aspartate transaminase $[\mathrm{AST}]$, alkaline phosphatase [ALP], creatine phosphokinase [CPK], gamma-glutamyltranferase [GGT], total bilirubin, blood urea nitrogen [BUN], creatinine, glucose, total serum protein, albumin, total calcium, magnesium, sodium, phosphorus, and potassium concentrations).

Cerebrospinal fluid (CSF) was aseptically collected from the lumbosacral site of each animal, as previously described [19]. CSF analysis was performed within $1 \mathrm{~h}$ of collection. Total nucleated cell count, differential cell count and total protein concentration were assessed.
Table 2 Classification of severity (score) of neurological findings in calves with otitis

\begin{tabular}{|c|c|}
\hline$\underline{\text { Score }}$ & Neurological findings \\
\hline & Mental Status \\
\hline 0 & Normal \\
\hline 1 & Depressed \\
\hline \multirow[t]{2}{*}{2} & Stuporous \\
\hline & Posture \\
\hline 0 & Normal \\
\hline 1 & Head tilt \\
\hline \multirow[t]{2}{*}{2} & Recumbent - unable to stand \\
\hline & Gait \\
\hline 0 & Normal \\
\hline 1 & Vestibular ataxia \\
\hline 2 & Hemiparesis/Hemiplegia \\
\hline \multirow[t]{2}{*}{3} & Tetraparesis/Tetraplegia \\
\hline & Proprioceptive Testing \\
\hline 0 & Normal \\
\hline 1 & Ipsilateral Decreased proprioceptive positioning reaction \\
\hline \multirow[t]{2}{*}{2} & Bilateral Decreased proprioceptive positioning reaction \\
\hline & Cranial Nerve Assessment \\
\hline 0 & No cranial nerve deficits \\
\hline $1^{a}$ & Anisocoria \\
\hline $1^{a}$ & Positional strabismus (III, IV, VI, VIII) \\
\hline $1^{\mathrm{a}}$ & Patological nystagmus (III, IV, VI, VIII) \\
\hline $1^{a}$ & Abnormal facial sensation perception $(V)$ \\
\hline $1^{\mathrm{a}}$ & Abnormal chewing and muscle tone $(V)$ \\
\hline \multirow[t]{2}{*}{$1^{a}$} & Ear droop, eyelid droop, upper lip droop \\
\hline & Absence of palpebral reflex and menace response (VII) \\
\hline $1^{\mathrm{a}}$ & Abnormal swallowing $(I X, X)$ \\
\hline $1^{\mathrm{a}}$ & Abnormal tongue size and asymmetry (XII) \\
\hline
\end{tabular}

Nasal and aural swabs were collected using sterile swabs from both nares and ears of each animal. Tracheobronchial aspiration (TBA) was performed as previously described [20]. Ear exudate was collected by means of a sterile disposable dog catheter $\left(2.0 \times 500 \mathrm{~mm}\right.$. Buster ${ }^{\oplus}$; Kruuse, Langeskov, Denmark) gently inserted through a sterile otoscope speculum into the affected ear canal and flushed with $2.5 \mathrm{~mL}$ of warm sterile saline solution. The aspirated fluid was then placed in a sterile tube. Aural, nasal and tracheobronchial samples were stored at $0-4{ }^{\circ} \mathrm{C}$ until processing.

Bacterial cultures and $M$. bovis identification were carried out at the Istituto Zooprofilattico Sperimentale della Lombardia e dell'Emilia Romagna (Brescia, Italy). Blood agar, brain heart infusion agar and MacConkey agar were used for bacteriological cultures. Cultures were incubated 
with $10 \% \mathrm{CO}_{2}$ at $37{ }^{\circ} \mathrm{C}$ for $24 / 48$ h. Mycoplasma cultures were performed on PPLO (pleuropneumonia-like organisms) bovine agar and broth and incubated for 7 days at $37^{\circ} \mathrm{C}$ in microaerophilic condition. M. bovis was identified by polymerase chain reaction (PCR) assay according to a validated method [21].

\section{Treatment}

All animals underwent a standardized therapeutic protocol at T0. Each calf received tulathromycin (Draxxin'; Zoetis) (single subcutaneous injection of $2.5 \mathrm{mg} / \mathrm{kg}$ ), oxytetracycline hydrochloride (Terramicina $100^{\circ}$; Zoetis) (intramuscular injection of $9.27 \mathrm{mg} / \mathrm{kg}$ for 5 consecutive days), and carprofen (Rimadyl ${ }^{\circ}$; Zoetis) (subcutaneous injection of $1.4 \mathrm{mg} / \mathrm{kg}$, repeated the fourth day). The referring veterinarian was instructed to continue the treatment from day 6 to 14 with an oral formulation containing oxytetracycline hydrochloride (10 mg/kg twice a day).

\section{Statistical analysis}

Statistical analysis was performed using the R2 1.0 freeware statistical software package (R Commander 2.0-4). The Shapiro-Wilk normality test was used to determine normal data distribution. Numerical data are presented as mean, frequency and/or percentage. A pairwise Wilcoxon rank sum test was used to assess the effect of treatment on clinical and neurological findings in relation to the experimental time points. Statistical significance was set at $P \leq 0.05$ and Bonferroni correction was applied for multiple comparisons.

\section{Results}

Twenty-two calves were enrolled in the study. The animals (18 males and 4 females, mean age 77 days, range 20-180) came from eight different herds. The breed types were Italian-Holstein Friesian $(n=9,41 \%)$, Piedmontese $(n=3,13 \%)$, Limousine $(n=1,5 \%)$, Belgian Blue $(n=1$, $5 \%)$, and cross-breed ( $n=8,36 \%) ; 16(73 \%)$ were referred during the autumn and winter and the remaining 6 (27\%) during the spring and summer months.

\section{Physical and neurological examination}

Physical and otoscopic examination at T0 revealed monolateral and bilateral otorrhea in 16 and 6 calves, respectively. Endoscopic examination was carried out by a single endoscopist (PG) at T0 in 11 calves. The tympanic membrane could not be visualized in any of the animals. Seventeen (77 \%) animals had abnormal neurological findings and five did not. The peripheral vestibular system was involved in all calves presenting with neurological signs. None of the animals showed signs of arthritis or a cranial nerve score $>5$. Figures 1 and 2 present the clinical and neurological findings at $\mathrm{T} 0$ and $\mathrm{T} 2$.

Head tilt and vestibular ataxia were the only posture and gait abnormalities observed, respectively. Positional strabismus and motor dysfunction of facial nerve (VII), alone or in combination, were the most common findings on cranial nerve assessment at each time point. A significant difference in the clinical (Fig. 3) and neurological (Fig. 4) scores was found between $\mathrm{T} 0$ and $\mathrm{T} 2$. A significant difference in the final total score was found between $\mathrm{T} 0$ and $\mathrm{T} 1$, and $\mathrm{T} 0$ and T2 (Fig. 5). Deterioration of neurological conditions

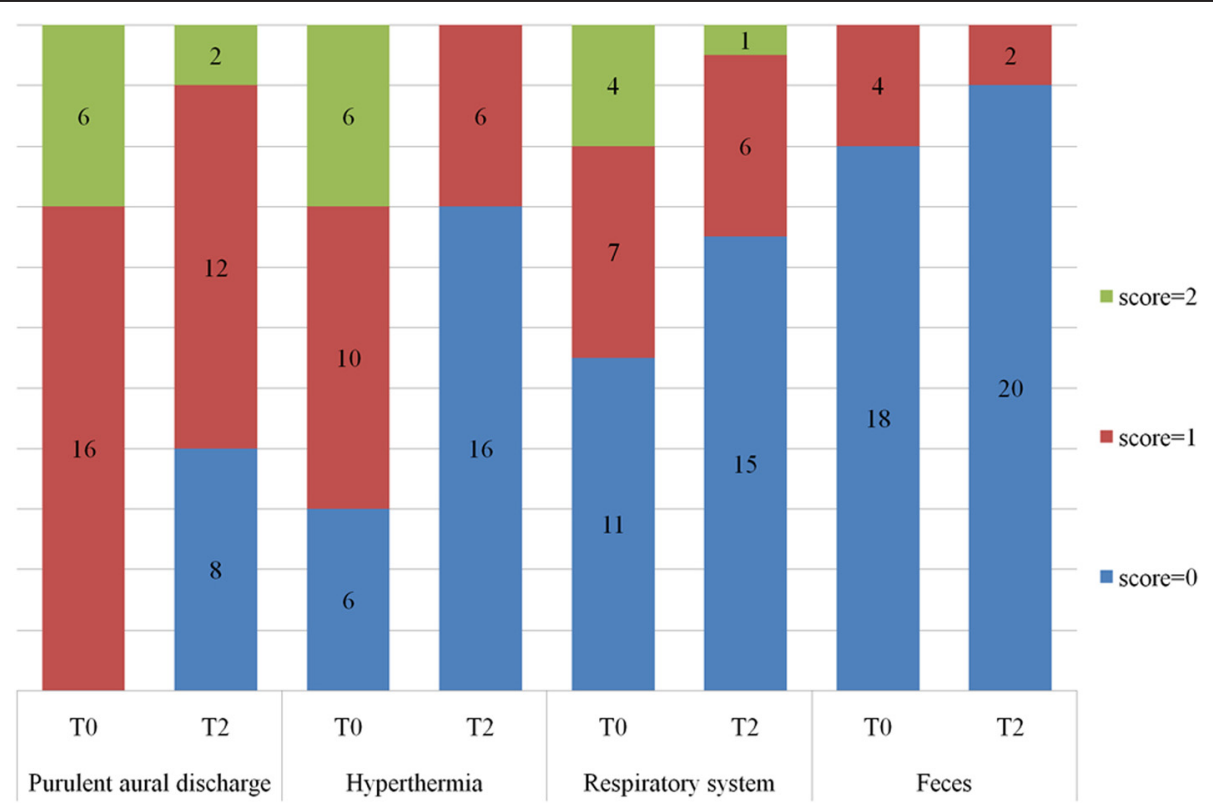

Fig. 1 Most common clinical findings at diagnosis (T0) and at 2 weeks after therapy (T2) 


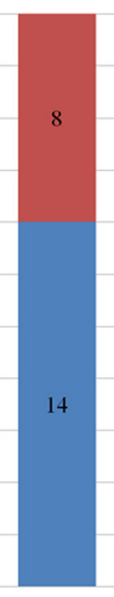

T0

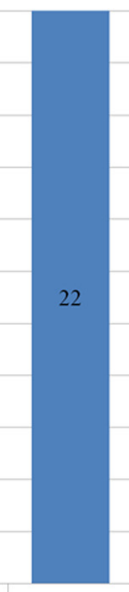

$\mathrm{T} 2$

Mental status

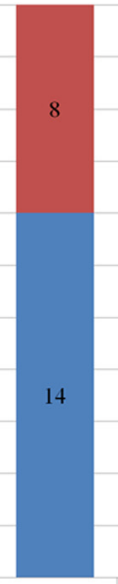

T0 Gait

$\mathrm{T} 2$

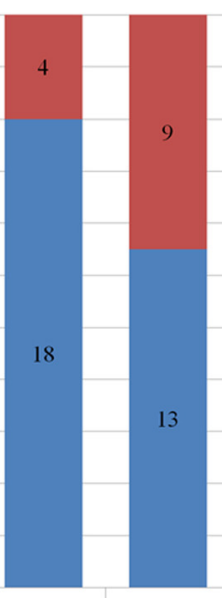

T0

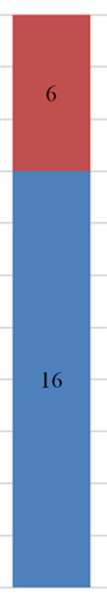

$\mathrm{T} 2$

Posture

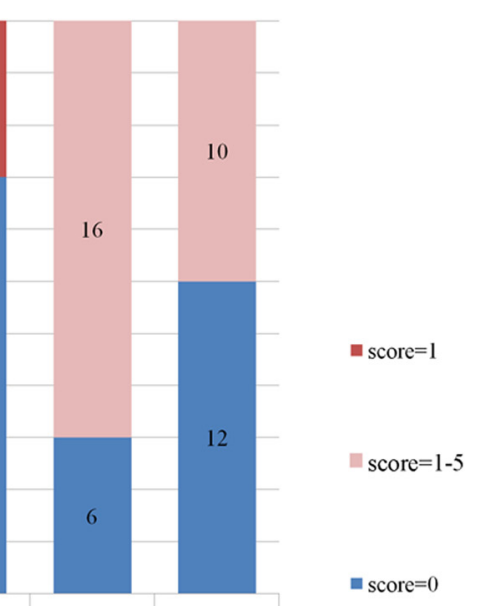

T0

$\mathrm{T} 2$

Cranial nerves assessment

Fig. 2 Most common neurological findings at diagnosis (T0) and 2 weeks after therapy (T2)

with central vestibular system deficits occurred in 1 calf between T0 and T1. For welfare reasons, the animal was treated with a different therapeutic protocol and excluded from assessment at $\mathrm{T} 2$.

A significant improvement of clinical and neurological scores was observed in $20(90 \%)$ calves, a full recovery in only 1 (5\%). No worsening of clinical conditions was observed or further treatments required at the onemonth follow-up. The agreement between neurological deficits and otoscopy was $77 \%$.

\section{Laboratory findings}

Hemocromocytometric and serum biochemical findings were unremarkable. CSF analysis of samples from 21 calves was abnormal in 5 (reference limits: total cell count $<10$

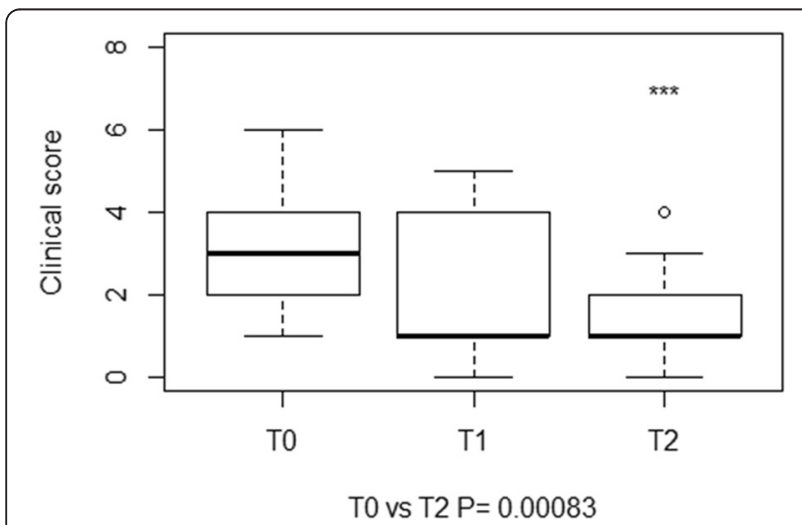

Fig. 3 Boxplots representation of clinical scores at T0, T1 and T2. The boxplots depict the minimum and maximum values, the upper (Q3) and lower (Q1) quartiles and the median. The median is identified by a line inside the box. The length of the box represents the interquartile range. Values that deviate appreciably from most of the measurements in the data set are labeled as outliers (o) cells $/ \mu \mathrm{L}$; microproteins $<40 \mathrm{mg} / \mathrm{dL}$ ). One sample was excluded due to severe blood contamination. Mild mononuclear pleocytosis was observed in CSF samples from 2 calves (total cell count 12 cells $/ \mu \mathrm{L}$ and microproteins $20.53 \mathrm{mg} / \mathrm{dL}$; total cell count 11 cells $/ \mu \mathrm{L}$ and microproteins $20.94 \mathrm{mg} / \mathrm{dL}$, respectively). Neutrophilic pleocytosis was found in CSF samples from 2 other calves (total cell count 95 cells $/ \mu \mathrm{L}$ and microproteins $163.2 \mathrm{mg} / \mathrm{dL}$; total cell count 50 cells $/ \mu \mathrm{L}$, microproteins $43.91 \mathrm{mg} / \mathrm{dL}$, respectively). Albuminocytological dissociation was detected in 1 animal (total cell count 8 cells $/ \mu \mathrm{L}$; microproteins $72.3 \mathrm{mg} / \mathrm{dL}$ ). Table 3 presents the results of bacterial and mycoplasmal cultures from affected ears, upper and lower respiratory tract.

Aural swabs and lavages tested positive for $M$. bovis in 79 and $89 \%$ of cases, respectively; the observed agreement

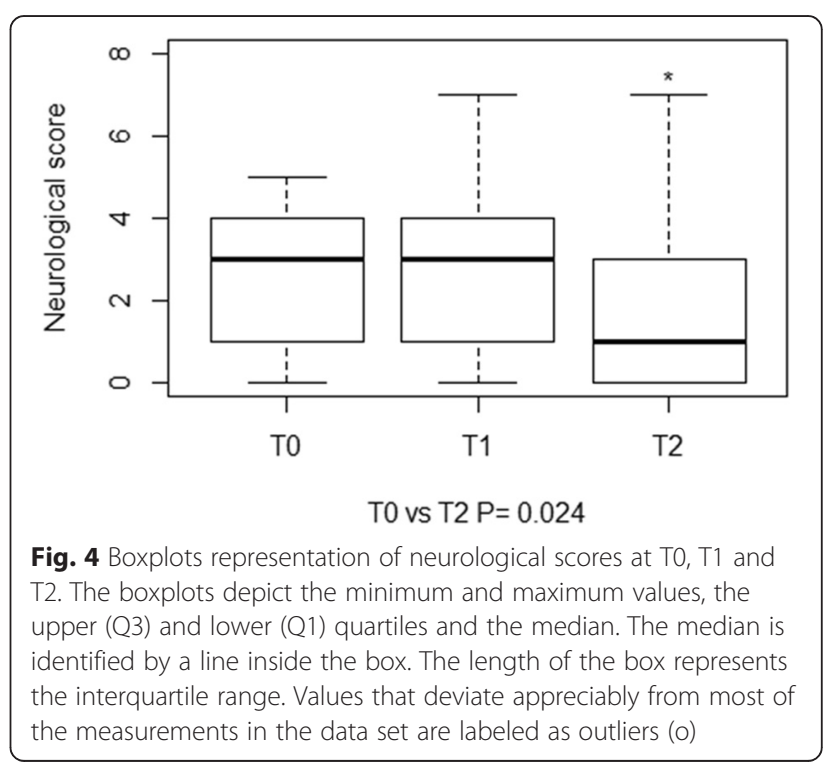




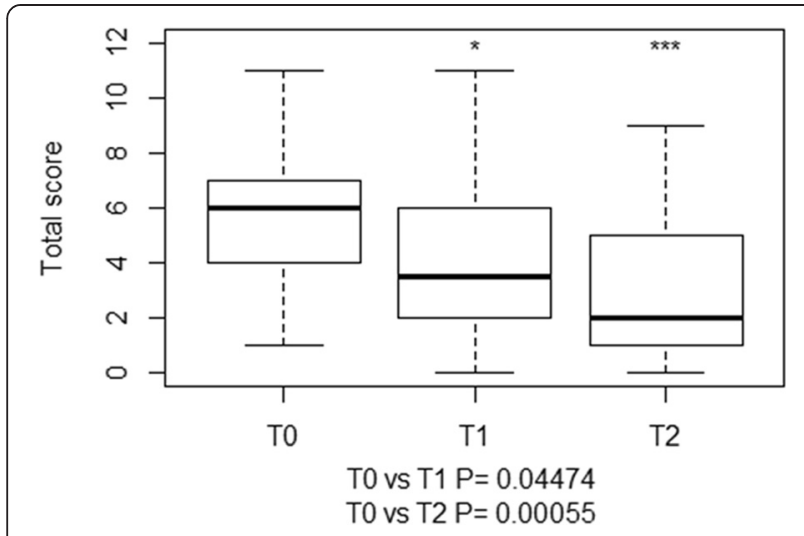

Fig. 5 Boxplots representation of the final total scores assigned at T0, T1, and T2. The boxplots depict the minimum and maximum values, the upper (Q3) and lower (Q1) quartiles and the median. The median is identified by a line inside the box. The length of the box represents the interquartile range. Values that deviate appreciably from most of the measurements in the data set are labeled as outliers (o)

between samples from aural swabs and lavages was $77 \%$. M. bovis was isolated in 3 out of 16 aural swabs collected from clinically healthy contralateral ears in association with Streptococcus $(n=1), P$. multocida $(n=1)$, and mixed bacterial flora $(n=1)$, respectively. Table 4 reports the distribution of the causative agents isolated from the ears and respiratory tract. Overall, M. bovis, either alone or together with another bacterial agent, was isolated from the upper and/or lower respiratory tract in 19 (86 \%) calves; M. bovis was isolated from the upper and/or lower respiratory tract in 10 out of 11 calves with respiratory signs.

\section{Discussion}

With this study we evaluated, in field conditions and by means of a simple scoring system, clinicopathological findings in calves with OM/OMI and the clinical efficacy of a standardized therapeutic protocol. Also, we identified associated causative agents and their possible correlation with concurrent BRD. As in previous studies [2, 5, 6], veal calves made up the majority of the study population, though the incidence of OMI in dairy calves seems to be rising $[6,10]$. Most reports state that males and females seem to be equally susceptible to the infection $[7,8,10]$; however, Lamm et al. [7] reported that males are more prone to $M$. bovis infection because they are fed poor quality milk and do not receive adequate colostrum. In the present study, the males far outnumbered the females (18 vs. 4) which is likely to be related with the type of breeding (veal calves) since males are reared more often than females. Seeking possible correlations between the consumption of wasted milk and the pathogenesis of OMI was beyond the scope of this study. Inclement weather seems to be a predisposing factor for the development of OM/OMI [5-9]. Indeed, the majority (73\%) of the calves were referred during the autumn and winter months.

The presenting complaints/clinical signs, neurological signs, and the frequency of unilateral/bilateral ear involvement were consistent with previous observations $[1,7,8,10,11,15]$; moreover, the persistence of mild clinical and neurological signs at $\mathrm{T} 2$ did not affect the animals' mental status, appetite or weight gain, as ascertained by telephone interviews with the owners. These findings are in line with evidence that animals tend to adapt and thrive despite the persistence of neurological signs $[8,10,22]$. Persistent head tilt seems to be a problem only in valuable animals $[8,10]$.

Scoring systems for the evaluation of gait, acute postoperative pain, and sepsis in cattle have been validated and found to be reliable and sensitive for assessing the severity of clinical signs [23, 24]. To the best of our knowledge, there are no validated scoring systems for evaluating clinical signs and/or response to therapy in

Table 3 Results of bacterial and mycoplasmal cultures

\begin{tabular}{|c|c|c|c|c|}
\hline \multirow[t]{3}{*}{ Bacterial colture results } & \multicolumn{2}{|c|}{ Affected Ears } & \multicolumn{2}{|c|}{ Respiratory tract } \\
\hline & Swabs & Lavages & Swabs & TBA \\
\hline & $n=28$ & $n=28$ & $n=22$ & $n=20$ \\
\hline M. bovis & 16 & 18 & 14 & 9 \\
\hline M. bovis and $P$. multocida & 5 & 5 & 2 & 3 \\
\hline M. bovis and Streptococcus spp. & 1 & - & 1 & - \\
\hline M. bovis and Staphylococcus spp. & - & 1 & - & - \\
\hline M. bovis and P. multocida + Streptococcus spp. & - & - & 1 & - \\
\hline M. bovis and Pseudomonas spp. & - & 1 & - & - \\
\hline Mycoplasma spp. & - & - & 2 & 1 \\
\hline P. multocida & 1 & - & - & - \\
\hline No bacteria & 4 & 1 & 1 & 7 \\
\hline Contaminated samples (not diagnostic) & 1 & 2 & 1 & - \\
\hline
\end{tabular}


Table 4 Distribution of the causative agents isolated from the ears and respiratory tract

\begin{tabular}{|c|c|c|c|c|c|c|}
\hline $\begin{array}{l}\text { Respiratory tract } \\
\text { Ears }\end{array}$ & M. bovis & $\begin{array}{l}\text { M. bovis + } \\
\text { P. multocida }\end{array}$ & $\begin{array}{l}\text { M. bovis + } \\
\text { Streptococcus spp. }\end{array}$ & $\begin{array}{l}\text { M. bovis + } \\
\text { Streptococcus spp. + } \\
\text { P. Multocida }\end{array}$ & Mycoplasma spp. & $\begin{array}{l}\text { Other mixed } \\
\text { bacteria }\end{array}$ \\
\hline M. bovis & $9\left(4^{\mathrm{a}} ; 1^{\mathrm{b}} ; 4^{\mathrm{c}}\right)$ & $1^{\mathrm{b}}$ & - & $1^{a}$ & $1^{c}$ & $1^{a}$ \\
\hline $\begin{array}{l}\text { M. bovis + } \\
\text { P. multocida }\end{array}$ & $2^{c}$ & $3\left(1^{a} ; 1^{b} ; 1^{c}\right)$ & - & - & $1^{a}$ & - \\
\hline $\begin{array}{l}\text { M. bovis + } \\
\text { Staphylococcus spp. }\end{array}$ & $1^{a}$ & - & - & - & - & - \\
\hline $\begin{array}{l}\text { M. bovis + } \\
\text { Streptococcus spp. }\end{array}$ & - & - & $1^{a}$ & - & - & - \\
\hline $\begin{array}{l}\text { M. bovis + } \\
\text { Pseudomonas spp. }\end{array}$ & $1^{\mathrm{a}}$ & - & - & - & - & - \\
\hline
\end{tabular}

calves with OM/OMI. Therefore, we applied two numerical scoring systems to objectively quantify clinical and neurological findings, respectively, at each experimental time point.

Abnormal CSF analysis results are suggestive of central nervous system (CNS) involvement [8]. None of the calves in the present study showed neurological signs consistent with central vestibular disease; however, the CSF abnormalities in five animals could be explained by a focal spread of infection to the CNS. Indeed, the inner ear communicates with the subarachnoid space through the cochlear canaliculus [25]. The use of diagnostic imaging, such as computed tomography (CT) or magnetic resonance imaging (MRI), could help to clarify this [26]. Unfortunately, this was not possible since the study was conducted in the field.

To date, different therapeutic approaches have been used in calves for the treatment of OM/OMI, but prospective studies evaluating the efficacy of a standardized protocol are lacking. Furthermore, because there are no licensed drugs for the treatment of these disorders, active against Mycoplasma spp., in calves, optimal therapy remains to be determined and extra-label drug use is required $[1,8]$. For the purpose of this survey, however, a randomized, double-blind placebo control study was not designed for ethical reasons and animal welfare, since meningitis and meningoencephalitis can develop secondary to the extension of infection $[1,10]$.

Our results suggest that, under the standardized therapeutic protocol applied in this study, the combined use of tulathromycin (Draxxin; Pfizer), oxytetracycline hydrochloride (Terramicina $100^{\circ}$; Zoetis), and carprofen (Rimadyl ${ }^{\oplus}$, Zoetis) might be effective for the treatment of $\mathrm{OM} / \mathrm{OMI}$ in calves. Significant clinico-neurological improvement was observed after 2 weeks of treatment in $95 \%$ of the calves and full recovery was achieved in only one animal. Prompt initiation of therapy (within 12-24 h after the onset of clinical signs) was probably key to symptom improvement since prognosis seems to be more favorable when therapy is begun early in the course of the disease $[2,9,27]$.

Tulathromycin, a novel, semi-synthetic macrolide bacteriostatic antimicrobial, is active against $M$. bovis and other bacterial respiratory pathogens in cattle. Following parenteral administration, it is rapidly adsorbed and widely distributed, and has a long elimination half-life in lung tissue [28]. It acts by inhibiting protein synthesis in susceptible microorganisms. Once penetrated into the bacterial cell, it irreversibly binds to receptors of the $30 \mathrm{~S}$ ribosomal subunits [29]. In a retrospective study [10], tulathromycin was administered for the treatment of OMI in calves, but no data about the number of treated animals or its efficacy are available. Oxyteracycline hydrochloride, a bacteriostatic, broad-spectrum tetracycline antibiotic, is widely distributed throughout the body. Although resistance of European mycoplasma strains to oxytetracycline has been reported [30, 31], it is effective against bacteria causing OMI, especially with prolonged use [11]. It acts similarly to tulathromycin by irreversibly binding to receptors of the $50 \mathrm{~S}$ ribosomal units [29]. In the present study tulathromycin and oxitetracycline hydrochloride have been used together as the association between bacteriostatic antibiotics can determine the summation of their individual effects [29]. Carprofen, a nonsteroidal anti-inflammatory drug, was added to antibiotic therapy to reduce rectal temperature and pain [1]. To date, combined use of anti-inflammatory drugs and antibiotics has been evaluated only in the treatment of BRD complex [32-34]; however, its efficacy is controversial [35].

As reported elsewhere, M. bovis, either alone or in association with P. multocida, Streptococcus spp., Staphylococcus spp. and Pseudomonas, was the most frequently isolated pathogen $[7,8,10]$. Indeed, it has been demonstrated that 
under opportune conditions many bacterial species colonize the middle ear [1]. Respiratory tract infections, often with the same pathogen, have been reported in calves with OMI $[1,2,8]$. Also in this study $M$. bovis was isolated from the upper and/or lower respiratory tract in 10 out of 11 calves with respiratory signs in which the OMI may have developed secondary to respiratory disease. The most common risk factor for OMI appears to be respiratory tract infections [1]: respiratory pathogens colonize the pharynx and tonsils and eventually the auditory tube, which represents the major route of infection in OMI [1]. The isolation of M. bovis, either alone or in association with other bacteria, from the aural swabs taken from the clinically healthy ears $(n=3)$ is in agreement with previous reports in which Mycoplasma spp. was harbored in the ears of apparently healthy animals [1]. As the host-mycoplasma relationship is complicated and many aspects of these interactions are poorly understood [36], further studies are needed to understand the role of this pathogen when its presence does not result in disease.

\section{Conclusion}

In conclusion, this is the first prospective study to evaluate the effectiveness of a standardized therapeutic protocol for the treatment of OM/OMI in calves. A significant improvement in symptoms was observed in the majority of the calves. The persistence of mild clinico-neurological signs did not compromise the animals' productive performance. The numerical scoring system for assessing clinical and neurological signs was a useful tool to objectively evaluate the response to therapy. $M$. bovis was the pathogen most often isolated. This finding should be considered when treating OM/OMI in calves. Also, respiratory tract infection should not be underrated, since it is one of the major risk factors for the development of OM/ OMI.

\section{Endnotes}

${ }^{1}$ Calf Respiratory Scoring Chart http://www.vetmed. wisc.edu/dms/fapm/fapmtools/8calf/calf_respiratory_ scoring_chart.pdf

\begin{abstract}
Abbreviations
ALP: Alkaline phosphatase; ALT: Alanine transaminase; AST: Aspartate aminotransferase; BUN: Blood urea nitrogen; BRD: Bovine respiratory disease; CBC: Complete blood count; CNS: Central nervous system; CPK: Creatine phosphokinase; CSF: Cerebrospinal fluid; CT: Computed tomography; GGT: Gamma-glutamyltranferase; MRI: Magnetic resonance imaging; OM: Otitis media; OMI: Otitis media-interna; TBA: Tracheobronchial aspiration.
\end{abstract}

\section{Competing interests}

The authors declare that they have no competing interests.

\section{Authors' contributions}

Conception and design: $\mathrm{ADA}, \mathrm{CB}, \mathrm{IB} ;$ Acquisition and interpretation of the data: $A D A, C B, G L A, I B, P G$; Collection and assembly of data: AC, ADA, CB, IB, ED, ML; Provision of study materials or patients: $A C, A R, C B, E D, G C, G L A, I B, M L, M M$; Statistical expertise: CB; Drafting the article: ADA, CB, GC, IB, PG; Critical revision of the article for important intellectual content: All authors. All authors read and approved the final manuscript. Acquisition of funding: ADA.

\section{Acknowledgements}

The present study was not financially supported.

\section{Author details}

${ }^{1}$ Department of Veterinary Science, University of Turin, Grugliasco, Italy. ${ }^{2}$ Diagnostic Section of Brescia, Istituto Zooprofilattico Sperimentale della Lombardia e dell'Emilia-Romagna, Brescia, Italy. ${ }^{3}$ Private Practitioner Turin, Turin, Italy. ${ }^{4}$ Private Practitioner Udine, Udine, Italy. ${ }^{5}$ Zoetis Italia, Rome, Italy. ${ }^{6}$ Private Practitioner Asti, Asti, Italy.

Received: 13 August 2015 Accepted: 24 November 2015

Published online: 03 December 2015

\section{References}

1. Morin DE. Brainstem and cranial nerve abnormalities: listeriosis, otitis media/ interna and pituitary abscess syndrome. Vet Clin North Am Food Anim Pract. 2004;20:243-73.

2. Jensen $R$, Maki LR, Lauerman LH, Raths WR, Swift BL, Flack DE, et al. Cause and pathogenesis of middle ear infection in young feedlot cattle. J Am Vet Med Assoc. 1983:182:967-72.

3. Foster AP, Naylor RD, Howie NM, Nicholas RAJ, Ayling RD. Mycoplasma bovis and otitis in dairy calves in the United Kingdom. Vet J. 2009;179:455-7.

4. Yeruham I, Elad D. Acute bilateral suppurative otitis media in a dairy cow. Can Vet J. 2004:45:79.

5. Nation PN, Frelier PF, Gifford GA, Carnat BD. Otitis in feedlot cattle. Can Vet J. $1983 ; 24: 238$.

6. Walz PH, Mullaney TP, Render JA, Walker RD, Mosser T, Baker JC. Otitis media in preweaned Holstein dairy calves in Michigan due to Mycoplasma bovis. J Vet Diagn Invest. 1997:9:250-4.

7. Lamm CG, Munson L, Thurmond MC, Barr BC, George LW. Mycoplasma otitis in California calves. J Vet Diagn Invest. 2004;16:397-402.

8. Francoz D, Fecteau G, Desrochers A, Fortin M. Otitis media in dairy calves: a retrospective study of 15 cases (1987 to 2002). Can Vet J. 2004;45:661-6.

9. Yeruham I, Elad D, Liberboim M. Clinical and microbiological study of an otitis media outbreak in calves in a dairy herd. J Vet Med B. 1999;46:145-50.

10. Bernier Gosselin V, Francoz D, Babkine M, Desrochers A, Nichols S, Doré E, et al. A retrospective study of 29 cases of otitis media/interna in dairy calves. Can Vet J. 2012;53:957-62

11. Van Biervliet J, Perkins GA, Woodie B, Pellegrini Massini A, Divers TJ, De Lahunta A. Clinical signs, computed tomographic imaging and management of chronic otitis media/interna in dairy calves. J Vet Intern Med. 2004;18:907-10.

12. Maunsell F, Brown MB, Powe J, Ivey J, Woolard M, Love W. Oral inoculation of young dairy calves with Mycoplasma bovis results in colonization of tonsils, development of otitis media and local immunity. Plos One. 2012;7:9.

13. Duarte ER, Hamdan JS. Otitis in cattle, an aetiological review. J Vet Med B. 2004:51:1-7.

14. Kawasaki Y, Takagi M, Fushimi Y, Mukai S, Yoshida T, Chuma T, et al. Bilateral otitis media with facial paralysis in a Japanese black calf. Vet Rec. 2009;165:212-3.

15. Maeda T, Shibahara T, Kimura K, Wada Y, Sato K, Imada Y, et al. Mycoplasma bovis-associated suppurative otitis media and pneumonia in bull calves. J Comp Pathol. 2003;129:100-10.

16. Finnen A, Blond L, Francoz D, Parent J. Comparison of computed tomography and routine radiography of the tympanic bullae in the diagnostic of otitis media in the calf. J Vet Intern Med. 2011;25:143-7.

17. Bernier Gosselin V, Babkine M, Gains MJ, Nichols S, Arsenault J, Francoz D. Validation of an ultrasound imaging technique of the tympanic bullae for the diagnosis of otitis media in calves. J Vet Intern Med. 2014;28(5):1594-601.

18. Buczinski S, Forté G, Francoz D, Bélanger AM. Comparison of thoracic auscultation, clinical score, and ultrasonography as indicators of bovine respiratory disease in preweaned dairy calves. J Vet Intern Med. 2014;28:234-42.

19. D’Angelo A, Miniscalco B, Bellino C, Bormida S, Borrelli A, Maurella A, et al. Analysis of cerebrospinal fluid from 20 calves after storage for 24 hours. Vet Rec. 2009;164:491-3.

20. Wilkins PA, Woolums AR. Disease of the respiratory system. In: Smith BP, editor. Large animal internal medicine. St. Louis: Mosby Elsevier; 2009. p. 503-4. 
21. Foddai A, Idini G, Fusco M, Rosa N, de la Fe C, Zinellu S, et al. Rapid differential diagnosis of Mycoplasma agalactiae and Mycoplasma bovis based on a multiplex-PCR and a PCR-RFLP. Mol Cell Probes. 2005;19:207-12.

22. Pardon B, Hostens M, Duchateau L, Dewulf J, De Bleecker K, Deprez P. Impact of respiratory disease, diarrhea, otitis and arthritis on mortality and carcass traits in white veal calves. BMC Vet Res. 2013:9:79.

23. Biolatti C, Bellino C, Borrelli A, Capucchio MT, Gianella P, Maurella C, et al, Sepsis and bacterial suppurative meningitis-meningoencephalitis in critically ill neonatal Piedmontese calves: clinical approach and laboratory findings. Schweiz Arch Tierheilkd. 2012;154(6):239-46.

24. de Oliveira FA, Luna SPL, do Amaral JV, Rodrigues KA, Sant'Anna AC, Daolio $M$, et al. Validation of the UNESP- Botucatu unidimensional composite pain scale for assessing postoperative pain in cattle. BMC Vet Res. 2014;10:200

25. De Lahunta A, Glass E. Vestibular system: Special proprioception. In: DeLahunta A, Glass E, editors. Veterinary Neuroanatomy and Clinical Neurology. St. Luis: Saunders Elsevier; 2009. p. 319-28.

26. Troxel MT, Drobatz KJ, Vite $\mathrm{CH}$. Signs of neurologic dysfunction in dogs with central versus peripheral vestibular disease. J Am Vet Med Assoc. 2005;227:570-4.

27. Maunsell FP, Woolums AR, Francoz D, Rosenbusch RF, Step DL, Wilson DJ, et al. Mycoplasma bovis infections in cattle. J Vet Intern Med. 2011;25:772-83.

28. Godinho KS, Rae A, Windsor GD, Tilt N, Rowan TG, Sunderland SJ. Efficacy of tulathromycin in the treatment and prevention of natural outbreaks of bovine respiratory disease in European cattle. Vet Ther. 2005;6:122-35.

29. Bellotti C. Macrolidi, lincosamidi e streptogramine. Pleuromutiline. Fenicolati. Rifamicine. In: Carli S, Ormas P, Re G, Soldani G, editors. Farmacologia Veterinaria. Napoli: Idelson- Gnocchi; 2009. p. 749-59.

30. Nicholas RAJ, Ayling RD. Mycoplasma bovis: disease, diagnosis, and control. Res Vet Sci. 2003;74:105-12

31. Thomas A, Nicolas C, Dizier I, Mainil J, Linden A. Antibiotic susceptibilities of recent isolates of Mycoplasma bovis in Belgium. Vet Rec. 2003;153:428-31.

32. Bednarek D, Zdzisinska B, Kondracki M, Kandefer-Szerszen M. Effect of steroidal and non-steroidal anti-inflammatory drugs in combination with long-acting oxytetracycline on non-specific immunity of calves sufferin from enzootic broncopneumonia. Vet Microbiol. 2003;96:53-67.

33. Deleforge J, Thomas E, Davot JL, Boisrame B. A field evaluation of the efficacy of tolfenamic acid and oxytetracycline in the treatment of bovine respiratory disease. J Vet Pharmacol Ther. 1994;17:43-5.

34. Lockwood PW, Johnson JC, Katz TL. Clinical efficacy of flunixin, carprofen and ketoprofen as adjuncts to the antibacterial treatment of bovine respiratory disease. Vet Rec. 2003;152:392-4.

35. Francoz D, Buczinski S, Apley M. Evidence related to the use of ancillary drugs in bovine respiratory disease (anti-inflammatory and others): are they justified or not? Vet Clin North Am Food Anim Pract. 2012;28:23-8.

36. Maunsell FP, Donovan GA. Mycoplasma bovis infections in young calves. Vet Clin North Am Food Anim Pract. 2009;25(1):139-77.

\section{Submit your next manuscript to BioMed Central and we will help you at every step:}

- We accept pre-submission inquiries

- Our selector tool helps you to find the most relevant journal

- We provide round the clock customer support

- Convenient online submission

- Thorough peer review

- Inclusion in PubMed and all major indexing services

- Maximum visibility for your research 